\title{
Ductal Carcinoma in situ: Underestimation of Percutaneous Biopsy and Positivity of Sentinel Lymph Node Biopsy in a Brazilian Public Hospital
}

\author{
Rafael da Silva Sá (1D ${ }^{1,2}$ \\ Angela Flávia Logullo (D) ${ }^{3}$ \\ Simone Elias $\mathbb{D}^{\prime}$ \\ Gil Facina iD ' \\ Vanessa Monteiro Sanvido (ID) \\ Afonso Celso Pinto Nazário (iD) \\ 'Department of Gynaecology, Breast \\ Surgery Team, Universidade Federal de \\ São Paulo (UNIFESP), São Paulo, Brazil; \\ ${ }^{2}$ Universidade do Oeste Paulista \\ (UNOESTE), Presidente Prudente, Brazil; \\ ${ }^{3}$ Department of Pathology, Universidade \\ Federal de São Paulo (UNIFESP), São \\ Paulo, Brazil
}

Background: Mammography screening has become widely spread and provided a marked increase in ductal carcinoma in situ (DCIS) diagnosis. In DCIS, the ductal epithelium proliferates without invasion through the basal cell membrane. However, histologic underestimation can happen in some cases.

Objective: To analyze the rate of histologic underestimation (histopathologic results upgraded to invasive carcinoma after surgery) and the rate of positive results of sentinel lymph node biopsy (SLNB) in patients diagnosed with DCIS in a Brazilian public hospital. Methods: We reviewed medical records of all consecutive patients admitted between 2009 and 2013 whose initial diagnosis was DCIS through core needle biopsy. DCIS cases with a high risk of invasion underwent SLNB. We excluded cases with invasion or micro-invasion components in the first biopsy.

Results: A total of 86 women were included, most with microcalcifications as the primary radiological lesion $(73.2 \%)$, and underwent preoperative biopsy, with an invasive component in $21(24.4 \%)$ in the final pathology report. Most had invasive carcinoma of no special type (NST): $52.3 \%(\mathrm{n}=11)$ and microinvasive tumors $(7$ cases, $33.3 \%)$. The main factors associated with histologic underestimation were nodular lesion $(61.9 \%, \mathrm{p}<0.001)$ and an ultra-sonography-guided biopsy $(71.4 \%, \mathrm{p}=0.0005)$. The positivity rate of SLNB was $4.3 \%$. All these patients underwent mastectomy, and the initial histologic pattern was solid DCIS. Conclusion: The "histologic underestimation" rate among patients with DCIS was not low, and less than $5 \%$ of patients who underwent SLNB had axillary positivity. This result suggests that patients who have DCIS and a high risk of invasion and undergoing mastectomy should have SLNB. As to the patients who will undergo lumpectomy, SLNB could be omitted and could be performed if patients have upgraded to invasive breast cancer.

Keywords: breast cancer, ductal carcinoma in situ, underestimation rates, positive sentinel lymph node

\section{Background}

Ductal carcinoma in situ (DCIS) is a pre-invasive lesion whose frequency of diagnosis has increased with the advent of mammographic screening. ${ }^{1}$ It corresponds to $25-30 \%$ of malignant breast malignant entities detected by mammography. ${ }^{2}$ As a malignant lesion confined within the breast duct, at least in theory, it has no possibility of regional or distant spread without local invasion of the basement membrane. ${ }^{3}$ However, some authors reported a benign mechanical cell transport through the lymphatics due to preoperative manipulation of the
Correspondence: Rafael da Silva Sá Surgery Team, Universidade Federal de São Paulo (UNIFESP), Rua Marselhesa, 249, São Paulo, SP, CEP 04020-060, Brazil Tel +55 I I 55764848

Email rafasamed@hotmail.com 
primary tumor, which would be a potential reason for positive lymph node findings among patients with DCIS. $^{4,5}$

Whenever radiologically suspicious lesions (categories 4 and 5 in the Breast Imaging-Reporting and Data System, BI-RADS) show up in screening mammography, a histological investigation is indicated. Percutaneous core needle biopsy is a less invasive alternative to surgical biopsy to obtain a histopathological diagnosis of breast cancer. ${ }^{6}$ However, this method is limited by histologic underestimation rates, when the biopsy sample contains only a ductal in situ component within the lesion and the final surgical specimen presents an upgrade to invasive carcinoma, which can reach up to $52 \%$ of cases in some reports. This rate is reduced with a vacuum-assisted biopsy approach to $18-23 \%{ }^{7}$

Although DCIS presents an excellent prognosis, with a 5-year overall survival rate of $98-100 \%$, relapse risk remains. ${ }^{8}$ The main invasion risk factors described in the literature are extensive lesions, palpable tumors with high histological grade, and the presence of comedonecrosis. ${ }^{9}$

Several authors have in the past supported the use of the sentinel lymph node biopsy (SLNB) technique in the first surgical procedure to provide a wider therapeutic approach for patients with DCIS. The latter are at risk of developing invasive carcinoma and avoid a new surgical procedure for the axillary approach. SNLB technique allows the surgeon to verify whether cancer has spread to the lymphatic system by injecting tracer material (a dye or radioactive solution) near the tumor and verifying if it drains to potentially affected nodes, which can be then removed. ${ }^{10}$

Although SLNB presents lower morbidity than lymphadenectomy, it nevertheless can lead to complications. SLNB can cause lymphedema, seroma, chronic pain, and patent blue $\mathrm{V}$ dye anaphylaxis. ${ }^{11}$ Even so, some breast surgeons do not advise performing SLNB in two stages due to some limitations, such as difficulty in migrating the dye used in the second surgery and the impossibility of performing it post-mastectomy. ${ }^{12}$

\section{Methods}

\section{Study Design, Setting, Size and Ethics}

We performed a retrospective study of a convenience sample containing all the consecutive patients admitted to the Mastology Clinic of a public university hospital in São Paulo, Brazil (São Paulo Hospital of Federal University of São Paulo) between January 1, 2009, and December 31,
2013, who had an initial DCIS diagnosis through a core needle biopsy. The institutional review board (Comitê de Ética em Pesquisa da Universidade Federal de São Paulo UNIFESP) approved the study protocol (under number 1.213.945/2015). Because this study was based exclusively on the review of medical records and pathology reports of patients cared in a university hospital and who routinely give informed consent for the procedures and the use of de-identified data in a proper form, specific informed consent for the research is exempted.

This study is reported according to the STROBE Statement (STrengthening the Reporting of OBservational studies in Epidemiology) reporting guideline and is in accordance with the Declaration of Helsinki.

\section{Participants}

Only patients initially diagnosed with pure DCIS and high risk of invasion (at least one criterion for high risk) were included in the study. Cases displaying invasive or microinvasive component in the biopsy and patients treated for breast cancer before were excluded.

All included patients were screened by mammography and sonogram using the same equipment, a GE Digital Senographe 2000 mammogram and A GE Logiq P6, equipped with a high-frequency linear transducer (12 $\mathrm{MHz}$ ) sonogram equipment. The biopsy instrument used was a Bard Magnum. In all cases, the procedure for sample collection was core needle biopsy (14 gauge). Minimally invasive procedures were performed with ultrasound or stereotactic guidance with the same equipment described.

According to the hospital's routine procedure protocol at the time, patients were selected for SLNB if they displayed a nodular lesion, microcalcifications length greater than $25 \mathrm{~mm}$, a nuclear grade 3 (independently of the type of surgery), or had already undergone a mastectomy procedure. Comedocarcinoma was not considered as a valid criterion for performing SLNB. The patent blue technique was used with the injection of $2 \mathrm{~mL}$ of the dye in the areolar region. Patients who had intraoperative positive frozen sample biopsies underwent lymphadenectomy. The axillary pathological status was defined according to the number of positive lymph nodes.

\section{Variables, Measurements and Analyses}

Patients whose pathology report of the percutaneous biopsy was indicative of DCIS and who displayed an invasive component in the final surgical pathological 
report were considered as underdiagnosed. These cases were registered for this study.

Immunohistochemical analysis was performed in all cases as a protocol hospital routine. The following measures were made and registered for this study:

- Estrogen and progesterone receptors expression with positivity indicating adjuvant endocrine therapy with tamoxifen, raloxifene, anastrozole or exemestane, ${ }^{13}$ evaluated using the Allred score from 0 to $8 ;^{14}$

- HER 2 overexpression (showing patients at higher risk for recurrence and invasion ${ }^{15}$ )

- Ki-67 mitotic index, ${ }^{16}$ with a cut-off value of $14 \%$.

In the underestimated cases, showing invasive carcinoma at the surgical report of final resection (detected by basement membrane invasion), the tumor grade was classified using the modified pathological Bloom-Richardson system. ${ }^{17}$ The staging was done according to the AJCC Cancer Staging Manual, 8th Edition, where women with pure DCIS are classified as Tis - Stage 0 (zero), the invasive underestimated cases as T1N0M0 - Stage I or T1N1M0 - Stage IIA. ${ }^{18}$

Data were collected and analyzed using Microsoft Excel software. Chi-square test or the $G$-test were used when appropriate. P-values were considered statistically significant at the $\alpha=5 \%$ level.

\section{Results}

\section{Participants' Demographics and Clinical Data}

A total of 86 patients were initially diagnosed with DCIS in the study period, all women. Their mean age was 58.3 years (range, 36-83). The left breast side was affected in $55.8 \%(\mathrm{n}=48)$, and two patients had bilateral lesions $(2.3 \%)$. The majority $(75.5 \%, \mathrm{n}=65)$ were already postmenopausal, as shown in Table 1.

The initial imaging findings (mammography and ultrasound) that led to the histopathological investigation were microcalcifications in most cases $(73.2 \% ; n=63)$; and all patients underwent preoperative minimally invasive biopsy with a core needle biopsy. And, 62.7\% $(\mathrm{n}=54)$ were subjected to stereotactic guidance, while $37.2 \%$ ( $\mathrm{n}=$ 32) were guided by sonogram.

Most DCIS presented comedocarcinoma $(48.8 \% ; \mathrm{n}=$ $42)$ and cribriform pattern $(45.3 \% ; n=39)$, as shown in
Figure 1 Nuclear grade 3 corresponded to $52.3 \%(n=45)$, was grade 2 in $32.5 \%(n=28)$, and nuclear grade 1 was present in only $15.1 \%(n=13)$ of the cases. The results of the immunohistochemistry analyses showing that most cases were estrogen and progesterone receptor expressing DCIS and HER2 negative.

The final pathology report, ie, the evaluation after therapeutic surgery, revealed an invasive component in 21 cases (24.4\%); and were considered underestimations. Of this total, 15 cases $(71.4 \%)$ had undergone core needle biopsy guided by ultrasound and $6(28.5 \%)$ with stereotactic guidance, as shown in Table 1 Most had invasive carcinoma of no special type (NST): $52.3 \%(\mathrm{n}=11)$; or microinvasive tumors ( 7 cases, 33.3\%), as shown in Figure 2.

\section{Main Study Results: Underestimation and Positivity Rate in SLNB}

The cases of underestimation were, in general, ER and PRpositive (positive for estrogen and progesterone receptors), HER2-negative and had a high Ki-67 index. Most of these women were postmenopausal. Grades and histological patterns of these cases are shown in the same Table 1.

The presence of a nodule $(61.9 \%, \mathrm{p}<0.001)$ and ultrasonography-guided biopsy $(71.4 \%, \mathrm{p}=0.0005)$ were significantly associated with the underestimated cases, as shown in Table 1.

Sixty-nine patients, representing $80.2 \%$ of patients initially diagnosed with DCIS, were included in the selection criteria for SLNB. Of these, 60.8\% $(n=42)$ underwent mastectomy, and 39.1\% $(\mathrm{n}=27)$ were at high risk for a subsequent invasive carcinoma and underwent lumpectomy, as shown in Table 2.

In the final surgical pathology report, three patients $(4.3 \%)$ presented axillary positivity and also invasive carcinoma of no special type (NST). Therefore, the positive rate of metastatic lymph nodes on SLNB for upgraded DCIS as invasive carcinoma is $14.2 \%$ (3/21). However, the vast majority $(95.6 \%, \mathrm{n}=67,1$ bilateral case) had negative axillary status, as shown in Figure 3.

Of 253 lymph nodes resected, 192 during were performed mastectomy (75.8\%) and 61 (24.1\%) during conservative breast surgery in patients at high risk for invasive carcinoma. Of these, $243(96 \%)$ were negative, and 10 $(3.9 \%)$ were positive. Of the three patients with positive lymph nodes cases, one case had the 12 nodes resected ( 7 positives), another patient had 4 nodes resected (1 
Table I Clinicopathologic Characteristics of the Entire Cohort by DCIS Status, Pure DCIS and Underestimation Cases

\begin{tabular}{|c|c|c|c|c|}
\hline Characteristics, n (\%) & Total Cases 86 (100\%) & Pure DCIS 65 (75.5\%) & Underestimation Cases 21 (24.4\%) & $P$-value \\
\hline \multicolumn{5}{|l|}{ Imaging findings } \\
\hline Microcalcifications & $63(73.2 \%)$ & $58(89.2 \%)$ & $05(23.8 \%)$ & \multirow[t]{3}{*}{$<0.001$} \\
\hline Lump & $20(23.3 \%)$ & 07 (10.7\%) & $13(61.9 \%)$ & \\
\hline Lump plus microcalcifications & 03 (3.4\%) & $00(0 \%)$ & $03(14.2 \%)$ & \\
\hline \multicolumn{5}{|l|}{ Lesion size } \\
\hline$<10 \mathrm{~mm}$ & $17(19.7 \%)$ & $15(23 \%)$ & 02 (9.5\%) & \multirow[t]{3}{*}{0.0876} \\
\hline $10-25 \mathrm{~mm}$ & $37(43 \%)$ & $30(46.1 \%)$ & 07 (33.3\%) & \\
\hline$>25 \mathrm{~mm}$ & $32(29 \%)$ & $20(30.7 \%)$ & $12(57.1 \%)$ & \\
\hline \multicolumn{5}{|l|}{ Breast density on mammogram } \\
\hline$A$ & $25(29 \%)$ & $20(30.7 \%)$ & $05(23.8 \%)$ & \multirow[t]{4}{*}{0.9779} \\
\hline B & 44 (51.1\%) & $34(52.3 \%)$ & $10(47.6 \%)$ & \\
\hline C & $22(25.5 \%)$ & $18(27.6)$ & $04(19 \%)$ & \\
\hline $\mathrm{D}$ & 09 (10.4\%) & 07 (10.7\%) & 02 (9.5\%) & \\
\hline \multicolumn{5}{|l|}{ Biopsy guidance } \\
\hline Stereotatic & $54(62.7 \%)$ & 48 (73.8\%) & 06 (28.5\%) & \multirow[t]{2}{*}{0.0005} \\
\hline Sonogram & 32 (37.2\%) & $17(26.1 \%)$ & I5 (7I.4\%) & \\
\hline \multicolumn{5}{|l|}{ Histologic subtype ${ }^{a}$} \\
\hline Comedocarcinoma & 42 (48.8\%) & 35 (53.8\%) & 07 (33.3\%) & \multirow[t]{4}{*}{0.7424} \\
\hline Cribriform & 39 (45.3\%) & 31 (47.6\%) & $08(38 \%)$ & \\
\hline Micropapillary & 15 (I7.4\%) & $13(20 \%)$ & 02 (9.5\%) & \\
\hline Solid & $36(41.8 \%)$ & 27 (4I.5\%) & 09 (42.8\%) & \\
\hline \multicolumn{5}{|l|}{ Nuclear grade } \\
\hline I & $13(15.1 \%)$ & 09 (I3.8\%) & 04 (19\%) & \multirow[t]{3}{*}{$0.784 I$} \\
\hline 2 & 28 (32.5\%) & 21 (32.3\%) & $08(38 \%)$ & \\
\hline 3 & 45 (52.3\%) & 35 (53.8\%) & $10(47.6 \%)$ & \\
\hline \multicolumn{5}{|l|}{ Estrogen receptor } \\
\hline Positive & 70 (81.3\%) & 53 (81.5\%) & 17 (80.9\%) & \multirow[t]{2}{*}{0.6323} \\
\hline Negative & $16(18.6 \%)$ & 12 (18.4\%) & 06 (28.5\%) & \\
\hline \multicolumn{5}{|l|}{ Progesterone receptor } \\
\hline Positive & 59 (68.6\%) & $44(67.6 \%)$ & I5 (7I.4\%) & \multirow[t]{2}{*}{0.9599} \\
\hline Negative & 27 (31.3\%) & 21 (32.3\%) & $06(28.5 \%)$ & \\
\hline \multicolumn{5}{|l|}{ HER 2} \\
\hline Negative $(0$ or I+) & $42(48.8 \%)$ & $28(43 \%)$ & $14(66.6 \%)$ & \multirow[t]{3}{*}{0.0640} \\
\hline Equivocal $(2+)$ & 09 (10.4\%) & 06 (9.2\%) & 3 (14.4\%) & \\
\hline Positive (3+) & $35(40.6 \%)$ & $31(47.6 \%)$ & $4(19 \%)$ & \\
\hline \multicolumn{5}{|l|}{ Ki67 index } \\
\hline$\leq 14 \%$ & 45 (52.3\%) & $36(55.3 \%)$ & 09 (42.8\%) & 0.4545 \\
\hline$>14 \%$ & 41 (47.6\%) & 29 (44.6\%) & $12(57.1 \%)$ & \\
\hline
\end{tabular}

(Continued) 
Table I (Continued).

\begin{tabular}{|c|c|c|c|c|}
\hline Characteristics, $\mathbf{n}(\%)$ & Total Cases 86 (100\%) & Pure DCIS 65 (75.5\%) & Underestimation Cases 21 (24.4\%) & P-value ${ }^{b}$ \\
\hline Left & $48(55.8 \%)$ & 38 (58.4\%) & $10(47.6 \%)$ & 0.6143 \\
\hline Right & $36(41.8 \%)$ & $26(40 \%)$ & $10(47.6 \%)$ & \\
\hline Bilateral & $02(2.3 \%)$ & $\mathrm{I}(\mathrm{l} .5 \%)$ & 01 (4.7\%) & \\
\hline \multicolumn{5}{|l|}{ Menstrual cycle } \\
\hline Menacme & $21(24.4 \%)$ & $15(23 \%)$ & $06(28.5 \%)$ & 0.8279 \\
\hline Postmenopausal & 65 (75.5\%) & $50(76.9 \%)$ & 15 (7|.4\%) & \\
\hline
\end{tabular}

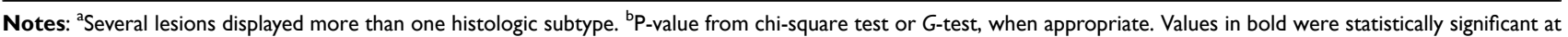
the $\alpha=5 \%$ level.

Abbreviation: DCIS, ductal carcinoma in situ.

positive), and the third patient also had 12 nodes removed (2 positives).

\section{Discussion}

\section{Key Results}

In this study, we estimated the "histologic underestimation", ie, the possibility of a pathological report, at the time of the first biopsy in patients with DCIS diagnosis, needing to be upgraded to invasive carcinoma at surgical specimen final report. In this context, we tried to evaluate the role of SNLB in the evaluation of patients selected for a biopsy after suspicious imaging exams. We found an underestimation rate of $24.4 \%$ and that only $4.3 \%$ of the patients who underwent SLNB presented positive axillary nodes. All these cases (4.3\%) presented positive SLNB and already had an indication to undergo mastectomy anyway.

\section{Interpretation}

Mammography is the best radiological examination for visualizing microcalcifications, which is the main DCIS

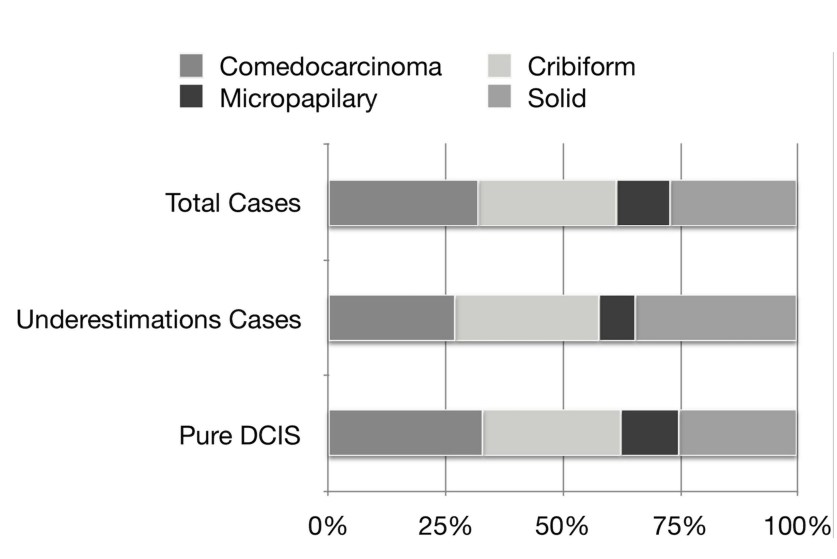

Figure I Histological subtypes of ductal carcinoma in situ. associated lesion. ${ }^{19}$ For many decades, before the implementation of annual mammographic screening, the rate of DCIS was $1 \%$ to $2 \%$ of all breast cancers. In our research, microcalcifications were the most common finding among the DCIS biopsy samples (73.2\%), which is consistent with most reports. ${ }^{8,20}$ This is why, although sonogram is more practical to guide percutaneous biopsy, most patients had to undergo stereotactic core needle biopsy.

The underestimation rate of $24.4 \%$ found in our study was similar to that reported in the literature. ${ }^{21,22}$ During the study period, vacuum biopsy (mammotomy), which uses larger caliber needles ( 9 gauge) and enables greater precision, was not available at the clinic. The high cost of

\section{- Invasive carcinoma of no special type - Invasive lobular carcinoma \\ Microinvasive \\ - Invasive papillary}

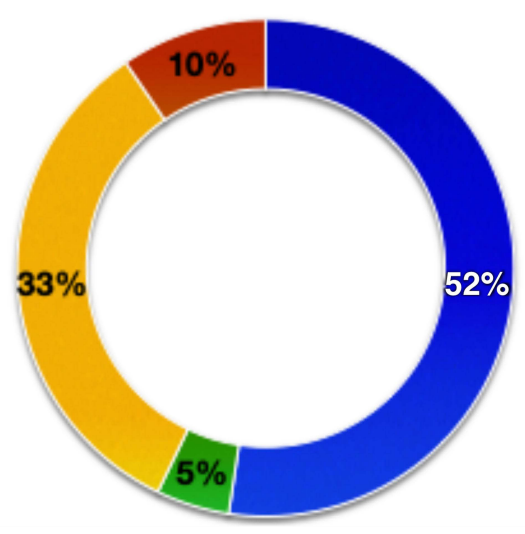

Figure 2 Histological subtypes in upstaged cases (final pathology confirming invasive or microinvasive patterns). 
Table 2 Clinicopathologic Characteristics of SLNB Cases

\begin{tabular}{|c|c|c|c|}
\hline Characteristics, n (\%) & $\begin{array}{c}\text { SLNB + } \\
03(4.3 \%)\end{array}$ & $\begin{array}{l}\text { SLNB - } \\
66 \\
(95.6 \%)\end{array}$ & P-value ${ }^{d}$ \\
\hline \multicolumn{4}{|l|}{ Imaging findings } \\
\hline $\begin{array}{l}\text { Microcalcifications } \\
\text { Nodule } \\
\text { Nodule plus } \\
\text { microcalcifications }\end{array}$ & $\begin{array}{c}0(0 \%) \\
2(66.6 \%) \\
I(33.3 \%)\end{array}$ & $\begin{array}{c}46(69.6 \%) \\
18(27.2 \%) \\
02(3 \%)\end{array}$ & 0.1059 \\
\hline \multicolumn{4}{|l|}{ Lesion size } \\
\hline $\begin{array}{l}<10 \mathrm{~mm} \\
10-25 \mathrm{~mm} \\
>25 \mathrm{~mm}\end{array}$ & $\begin{array}{c}00(0 \%) \\
00(0 \%) \\
03(100 \%)\end{array}$ & $\begin{array}{l}14(21.2 \%) \\
27(40.9 \%) \\
25(37.8 \%)\end{array}$ & 0.1057 \\
\hline \multicolumn{4}{|l|}{ Histologic subtype ${ }^{a}$} \\
\hline $\begin{array}{l}\text { Comedocarcinoma } \\
\text { Cribriform } \\
\text { Micropapillary } \\
\text { Solid }\end{array}$ & $\begin{array}{c}00(0 \%) \\
00(0 \%) \\
00(0 \%) \\
03(100 \%)\end{array}$ & $\begin{array}{l}34(51.5 \%) \\
30(45.4 \%) \\
1015.1 \%) \\
33(50 \%)\end{array}$ & 0.1704 \\
\hline \multicolumn{4}{|l|}{ Type of surgery } \\
\hline $\begin{array}{l}\text { Mastectomy } \\
\text { Lumpectomy }\end{array}$ & $\begin{array}{c}03(100 \%) \\
00(0 \%)\end{array}$ & $\begin{array}{c}39(59 \%) \\
27(40.9 \%)\end{array}$ & 0.3878 \\
\hline \multicolumn{4}{|l|}{ Upstaged subtype ${ }^{\mathrm{b}}$} \\
\hline $\begin{array}{l}\mathrm{NST}^{\mathrm{c}} \\
\text { Invasive lobular carcinoma } \\
\text { Microinvasive } \\
\text { Invasive papillary }\end{array}$ & $\begin{array}{l}03(100 \%) \\
00(0 \%) \\
00(0 \%) \\
00(0 \%)\end{array}$ & $\begin{array}{c}08(12.1 \%) \\
01(1.5 \%) \\
07(10.6 \%) \\
02(4.5 \%)\end{array}$ & 0.4587 \\
\hline \multicolumn{4}{|l|}{ Estrogen receptor } \\
\hline $\begin{array}{l}\text { Positive } \\
\text { Negative }\end{array}$ & $\begin{array}{l}02(66.6 \%) \\
01(33.3 \%)\end{array}$ & $\begin{array}{l}55(83.3 \%) \\
\text { II (16.6\%) }\end{array}$ & 0.9728 \\
\hline \multicolumn{4}{|l|}{ Progesterone receptor } \\
\hline $\begin{array}{l}\text { Positive } \\
\text { Negative }\end{array}$ & $\begin{array}{l}02(66.6 \%) \\
01(33.3 \%)\end{array}$ & $\begin{array}{l}48(72.7 \%) \\
18(27.2 \%)\end{array}$ & 0.6509 \\
\hline \multicolumn{4}{|l|}{ HER 2} \\
\hline $\begin{array}{l}\text { Negative }(0 \text { or } 1+) \\
\text { Equivocal }(2+) \\
\text { Positive }(3+)\end{array}$ & $\begin{array}{c}02(66.6 \%) \\
00(0 \%) \\
01(33.3 \%)\end{array}$ & $\begin{array}{l}27(40.9 \%) \\
19(28.7 \%) \\
20(30.3 \%)\end{array}$ & 0.4288 \\
\hline \multicolumn{4}{|l|}{ Ki67 index } \\
\hline $\begin{array}{l}\leq 14 \% \\
>14 \%\end{array}$ & $\begin{array}{l}01(33.3 \%) \\
02(66.6 \%)\end{array}$ & $\begin{array}{l}34 \text { (5I.5\%) } \\
32 \text { (48.4\%) }\end{array}$ & 0.9795 \\
\hline
\end{tabular}

Notes: ${ }^{\text {aS }}$ everal lesions displayed more than one histologic subtype. ${ }^{\mathrm{b}}$ Total of

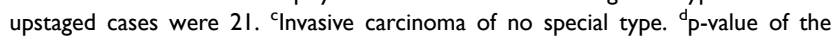
G-test.

Abbreviation: SLNB, sentinel lymph node biopsy. $\because \mathrm{SLNB}+\quad \quad$ SLNB -

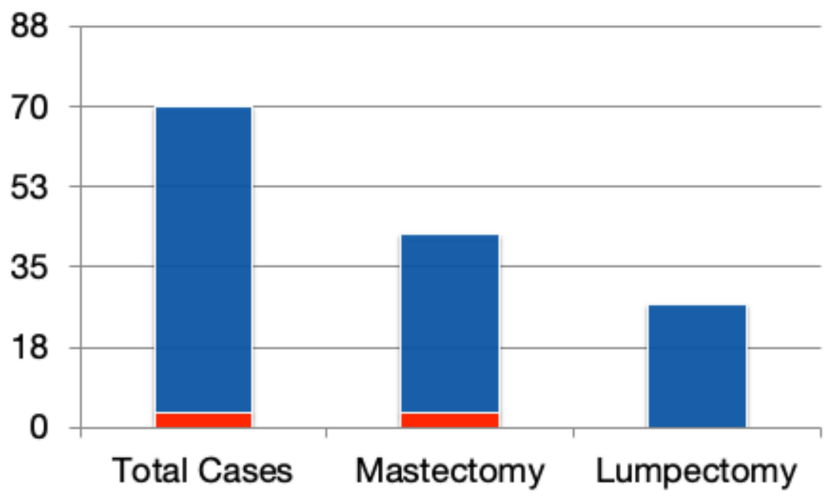

Figure 3 Sentinel lymph node biopsy results in patients with ductal carcinoma in situ.

the mammotomy needle device limits access to this technique in Brazilian public institutions. The advent of this technology could have potentially decreased the underdiagnosis rate even further. ${ }^{7}$

Nearly all patients had more than one histological pattern of ductal carcinoma in situ, showing a variety of histological subtypes that may be involved in the same lesion. The main subtype found was comedocarcinoma. Although some authors consider comedocarcinoma as a high-risk criterion for invasion, in this cohort, we did not observe this association, and if this criterion had been adopted, many more patients would have been considered for SLNB unnecessarily. ${ }^{23}$

Some newer devices may reduce histological underestimation. Meurs et al evaluated 2892 patients with DCIS and developed a free-to-use software for the prediction of the risk for underestimation of invasive breast cancer after a DCIS diagnosis by biopsy. The model selects high-risk lesion considering the detection mode (screening or individual diagnostic), if the lesion is palpable, the BI-RADS category (3-5), the DCIS grade and the suspicion of an invasive component. ${ }^{22}$ The authors interpreted that lesions with a high-risk score have a good chance of a final diagnosis of DCIS. However, in that study, minimal-volume DCIS is removed from the biopsy itself, which can be associated with underestimation. The authors tested the model in their sample, but the algorithm still needs external validation. Furthermore, the model does not consider the biopsy device used or the size of 
the lesion on mammography, which could interfere with the results.

To date, the application of SLNB in DCIS cases remains controversial. ${ }^{24}$ The indications for SLNB in DCIS among North American, British and Dutch cancer guidelines include patients at high risk of invasion or in the event of mastectomy. High risk of invasion is defined by the presence of a palpable solid tumor, extensive calcifications, tumor diameter greater than $25 \mathrm{~mm}$, high-grade DCIS and age below 55 years. ${ }^{25-27}$ However, Chehade et al carried out a meta-analysis with 48 studies on SLNB in DCIS, concluding that it should be performed only in high-grade DCIS greater than $20 \mathrm{~mm}^{28}$

In the 1990s, several surgeons performed routine SLNB in DCIS cases. ${ }^{29}$ However, the vast majority are currently performing it only at mastectomy and in cases at high risk for invasion. ${ }^{2,30}$ The number of surgeons who have discontinued the use of SLNB during breast conservative surgery, reserving this technique only for mastectomy cases, is increasing. ${ }^{28,31}$

Our results show that only $4.3 \%$ of all patients who underwent SLNB had axillary positive lymph nodes, and all of these were patients who underwent a mastectomy. That is, all patients who had an indication for SLNB during lumpectomy had no lymph node metastasis, including the seven cases $(33.3 \%)$ that were part of the "underestimation group". We found ductal carcinoma in situ with a solid pattern in all cases of positive SLNB, but without statistical significance $(\mathrm{p}=0.1704)$. The solid histologic subtype needs further study, as it was related to most cases of underestimation and was the initial lesion in cases with axillary metastasis. All underestimated cases of microinvasive carcinoma also had negative axillary status. Therefore, the resection of 61 lymph nodes (total of lymph nodes resected during lumpectomy of high-risk patients for invasion) could have been avoided. In 100\% of the cases of lymph node metastasis, the initial histologic pattern was solid DCIS.

\section{Limitations and Generalizability}

This is a retrospective study that, per nature, would not allow us to determine causality. However, its results clearly show that a clinical trial evaluating the role of lymph node biopsy in cases of conservative breast surgery is not necessary nor warranted.

During the study period, our institution had no access to a vacuum-assisted biopsy device. Unfortunately, many public hospitals in poor and developing countries cannot afford expensive technologies, needing to use de core needle biopsy routinely, due to its low cost in all cases. The absence of data from mammotomies, with higher availability of tissue for analysis, might have added some imprecision to the results. However, this is possibly the reality of hospitals in other low-resourced regions. This is a limitation of our service, rather than of our study, and more resourceful services could investigate if these technologies would improve the results.

We are living in an era of de-escalation of breast cancer treatment. In the coming years, we may have a radical change in the treatment of DCIS. PRECISION Trial and other randomized clinical studies aim to avoid breast surgery altogether in DCIS, performing vacuum-assisted excision only. ${ }^{32}$ It remains to be determined if this type of technology will have wide availability. For now, it seems that our results could be generalized to other lowresourced centers and regions only.

The goal of the breast surgeon, whilst increasing overall and disease-free survival of his or her patient, is to decrease maximum morbidity, providing greater comfort and quality of life. Despite all the recent diagnostic and therapeutic advances, the ideal management of DCIS is still unclear. Studies that can guide individual management should be performed. Perhaps in the near future, genetic markers will help to select the patients that really need more aggressive procedures, surgical, radiotherapeutic, or systemic.

\section{Conclusions}

This study confirmed the histologic underestimation rate among patients with DCIS reported in the literature: it was $24.4 \%$. Only $4.3 \%$ of patients who underwent SLNB had axillary positivity, and all these patients had to undergo mastectomy anyway. Patients who have DCIS and high risk of invasion and undergoing mastectomy should have SLNB. As to the patients who will undergo lumpectomy, SLNB could be omitted and could be performed if the diagnosis has been changed to invasive breast cancer.

\section{Abbreviations}

DCIS, ductal carcinoma in situ; SLNB, sentinel lymph node biopsy; BI-RADS, Breast Imaging-Reporting and Data System; ER, estrogen receptor; PR, progesterone receptor; NST, no special type; LCIS, lobular carcinoma in situ. 


\section{Data Sharing Statement}

The datasets used and/or analyzed during the current study are available from the corresponding author on reasonable request.

\section{Acknowledgments}

The authors thank Patricia Logullo for the assistance with text editing and Suelen Umbelino da Silva for the assistance with statistical analysis.

\section{Author Contributions}

Rafael Silva Sá contributed with study design (conceptualization), methodology, investigation, data collection (curation) and formal analysis, project administration, writing of original draft, reviewing and editing and approval of the last version to be published. Angela Flavia Logullo Waitzberg contributed with the investigation, data collection (curation) and formal analysis, critical review of the manuscript and approval of the last version to be published. Simone Elias contributed with the investigation, data collection (curation) and formal analysis, critical review of the manuscript and approval of the last version to be published. Gil Facina contributed with the investigation, data collection (curation) and formal analysis, critical review of the manuscript and approval of the last version to be published. Vanessa Monteiro Sanvido contributed with writing, reviewing and editing and approval of the last version to be published. Afonso Celso Pinto Nazário contributed with study design (conceptualization), methodology, critical review and editing, and approval of the last version to be published. All authors made substantial contributions to conception and design, acquisition of data, or analysis and interpretation of data; took part in drafting the article or revising it critically for important intellectual content; agreed to submit to the current journal; gave final approval of the version to be published; and agree to be accountable for all aspects of the work.

\section{Funding}

The authors declare that this study received no funding.

\section{Disclosure}

The authors declare that there are no conflicts of interest involved in this study.

\section{References}

1. Silverstein MJ, Poller DN, Waisman JR, et al. Prognostic classification of breast ductal carcinoma-in-situ. Lancet. 1995;345:1154-1157. doi:10.1016/S0140-6736(95)90982-6
2. Trentin C, Dominelli V, Maisonneuve P, et al. Predictors of invasive breast cancer and lymph node involvement in ductal carcinoma in situ initially diagnosed by vacuum-assisted breast biopsy: experience of 733 cases. Breast. 2012;21(5):635-640. doi:10.1016/j. breast.2012.06.009

3. Jansen SA. Ductal carcinoma in situ: detection, diagnosis, and characterization with magnetic resonance imaging. Semin Ultrasound $C T$ MR. 2011;32(4):306-318. doi:10.1053/j.sult.2011.02.007

4. Carter BA, Jensen RA, Simpson JF, Page DL. Benign transport of breast epithelium into axillary lymph nodes after biopsy. Am J Clin Pathol. 2000;113(2):259-265. doi:10.1309/7EF8-F1W7-YVNT-H8H5

5. Tvedskov TF, Jensen MB, Kroman N, Balslev E. Iatrogenic displacement of tumor cells to the sentinel node after surgical excision in primary breast cancer. Breast Cancer Res Treat. 2012;131:223-229. doi:10.1007/s10549-011-1720-y

6. Bassett LW, Mahoney MC, Apple SK. Interventional breast imaging: current procedures and assessing for concordance with pathology. Radiol Clin North Am. 2007;45(5):881-894. doi:10.1016/j. rcl.2007.06.010

7. Lee JM, Kaplan JB, Murray MP, et al. Underestimation of DCIS at MRI-guided vacuum-assisted breast biopsy. AJR Am J Roentgenol. 2007;189(2):468-474. doi:10.2214/AJR.07.2172

8. Wickerham DL. Ductal carcinoma-in-situ. J Clin Oncol. 2001;19 (suppl):98S-100S.

9. Silverstein MJ, Lagios MD, Craig PH, et al. A prognostic index for ductal carcinoma in situ of the breast. Cancer. 1996;77:2267-2274. doi:10.1002/(SICI)1097-0142(19960601)77:11<2267::AIDCNCR13>3.0.CO;2-V

10. Kim T, Giuliano AE, Lyman GH. Lymphatic mapping and sentinel lymph node biopsy in early-stage breast carcinoma: a metaanalysis. Cancer. 2006;106(1):4-16. doi:10.1002/cncr.21568

11. Wilke LG, McCall LM, Posther KE, et al. Surgical complications associated with sentinel lymph node biopsy: results from a prospective international cooperative group trial. Ann Surg Oncol. 2006;13:491-500. doi:10.1245/ASO.2006.05.013

12. Feldman SM, Krag DN, McNally RK, Moor BB, Weaver DL, Klein P. Limitation in gamma probe localization of the sentinel node in breast cancer patients with large excisional biopsy. $J \mathrm{Am}$ Coll Surg. 1999;188:248-254. doi:10.1016/S1072-7515(98)00306-8

13. Wan ZB, Gao HY, Wei L, et al. Expression of estrogen receptor, progesterone receptor, human epidermal growth factor receptor 2, and Ki-67 in ductal carcinoma in situ (DCIS) and DCIS with microinvasion. Medicines. 2018;97(44):e13055. doi:10.1097/ MD.0000000000013055

14. Allred DC, Anderson SJ, Paik S, et al. Adjuvant tamoxifen reduces subsequent breast cancer in women with estrogen receptor-positive ductal carcinoma in situ: a study based on NSABP protocol B-24. $J$ Clin Oncol. 2012;30(12):1268-1273. doi:10.1200/JCO.2010.34.0141

15. Roses RE, Paulson EC, Sharma A, et al. HER-2/neu overexpression as a predictor for the transition from in situ to invasive breast cancer. Cancer Epidemiol Biomarkers Prev. 2009;18(5):1386-1389. doi:10.1158/1055-9965.EPI-08-1101

16. Daltoé RD, Madeira KP, de Carvalho AA, de Rezende LC, Silva IV, Rangel LB. Evaluation of the progesterone receptor status in breast cancer using three different antibodies: a comparison by Allred score system. Int J Clin Exp Pathol. 2013;7(1):331-339.

17. Elston CW, Ellis IO. Pathological prognostic factors in breast cancer. I. The value of histological grade in breast cancer: experience from a large study with long-term follow-up. Histopathology. 1991;19:403-410. doi:10.1111/j.1365-2559.1991.tb00229.x

18. American Joint Committee on Cancer (AJCC). Cancer Staging Manual. 8th ed. Springer; 2016.

19. Duffy SW, Tabár L, Yen AM-F, et al. Mammography screening reduces rates of advanced and fatal breast cancers: results in 549,091 women. Cancer. 2020;126(13):2971-2979. doi:10.1002/ cncr.32859 
20. Patani N, Khaled Y, Al Reefy S, Mokbel K. Ductal carcinoma in-situ: an update for clinical practice. Surg Oncol. 2011;20(1):e23-e31. doi:10.1016/j.suronc.2010.08.007

21. Chavez de Paz Villanueva C, Bonev V, Senthil M, et al. Factors associated with underestimation of invasive cancer in patients with ductal carcinoma in situ: precautions for active surveillance. JAMA Surg. 2017;152(11):1007-1014. doi:10.1001/jamasurg.2017.2181

22. Meurs CJC, van Rosmalen J, Menke-Pluijmers MBE, et al. A prediction model for underestimation of invasive breast cancer after a biopsy diagnosis of ductal carcinoma in situ: based on 2892 biopsies and 589 invasive cancers. $\mathrm{Br} J$ Cancer. 2018;119:1155-1162. doi:10.1038/s41416-018-0276-6

23. Page DL, Steel CM, Dixon JM. ABC of breast disease. Carcinoma in situ and patients at high risk of breast cancer. $\mathrm{Br}$ Med $\mathrm{J}$. 1995;310:39-42. doi:10.1136/bmj.310.6971.39

24. Lyman GH, Somerfield MR, Bosserman LD, Perkins CL, Weaver DL, Giuliano AE. Sentinel lymph node biopsy for patients with early-stage breast cancer: American Society of Clinical Oncology Clinical Practice Guideline Update. Sentinel lymph node biopsy for patients with early-stage breast cancer: American Society of Clinical Oncology Clinical Practice Guideline Update. J Clin Oncol. 2017;35(5):561-564. doi:10.1200/JCO.2016.71.0947

25. Kaufman SA, Harris EE, Bailey L, et al. ACR appropriateness criteria(R) ductal carcinoma in situ. Oncology. 2015;29(6):446-458, 441-460.

26. National Breast Cancer Organization Netherlands (NABON). Evidence-based richtlijn Mammacarcinoom. Version 2.0. 2012 Available from: http://www.oncoline.nl/. Assessed September 20, 2020 .
27. Harnett A, Smallwood J, Titshall V, Champion A; Guideline Development G. Diagnosis and treatment of early breast cancer, including locally advanced disease-summary of NICE guidance. BMJ. 2009;338:b438. doi:10.1136/bmj.b438

28. Chehade HEH, Headon H, Wazir U, Abtar H, Kasem A, Mokbel K. Is sentinel lymph node biopsy routinely indicated in patients with a diagnosis of ductal carcinoma in situ? A systematic literature review and meta-analysis. Am $J$ Surg. 2017;213:171-180. doi:10.1016/j.amjsurg.2016.04.019

29. Lucci A Jr, Kelemen PR, Miller CIII, et al. National practice patterns of sentinel lymph node dissection for breast carcinoma. J Am Coll Surg. 2001;192:453-458. doi:10.1016/S1072-7515(01)00798-0

30. Park HS, Park S, Cho J, et al. Risk predictors of underestimation and the need for sentinel node biopsy in patients diagnosed with ductal carcinoma in situ by preoperative needle biopsy. J Surg Oncol. 2013;107(4):388-392. doi:10.1002/jso.23273

31. Price A, Schnabel F, Chun J, et al. Sentinel lymph node positivity in patients undergoing mastectomies for ductal carcinoma in situ (DCIS). Breast J. 2020;26(5):931-936. doi:10.1111/tbj.13737

32. Collyar D, Pinto D, Stobart H, Verschuur E, van Oirsouw M. How patient advocates and researchers work together in PRECISION* to identify low-risk ductal carcinoma in situ (DCIS) that may not need aggressive treatment. Cancer Res. 2020;80(4 Supplement):P1-16-04. doi:10.1158/1538-7445.SABCS19-P1-16-04

\section{Publish your work in this journal}

Breast Cancer - Targets and Therapy is an international, peer-reviewed open access journal focusing on breast cancer research, identification of therapeutic targets and the optimal use of preventative and integrated treatment interventions to achieve improved outcomes, enhanced survival and quality of life for the cancer patient.
The manuscript management system is completely online and includes a very quick and fair peer-review system, which is all easy to use. Visit http://www.dovepress.com/testimonials.php to read real quotes from published authors. 